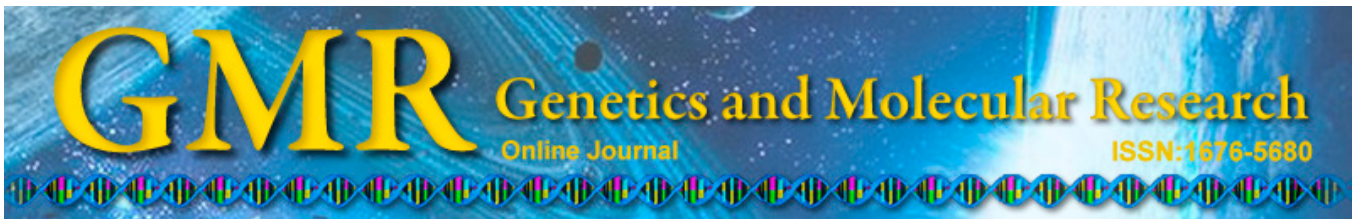

\title{
Efficacy of Artemisia annua polysaccharides as an adjuvant to hepatitis $C$ vaccination
}

\author{
L.D. Bao ${ }^{1}$, X.H. Ren ${ }^{1}$, R.L. Ma ${ }^{1}$, Y. Wang ${ }^{1}$, H.W. Yuan ${ }^{2}$ and H.J. Lv \\ ${ }^{1}$ Department of Pharmacy, \\ Affiliated Hospital of Inner Mongolia Medical University, Hohhot, China \\ ${ }^{2}$ Department of Pathology, \\ Affiliated Hospital of Inner Mongolia Medical University, Hohhot, China \\ ${ }^{3}$ Department of Scientific Research, \\ Affiliated Hospital of Inner Mongolia Medical University, Hohhot, China \\ Corresponding authors: H.J. Lv/ H.W. Yuan \\ E-mail: 1vhaijundsr@163.com
}

Genet. Mol. Res. 14 (2): 4957-4965 (2015)

Received August 12, 2014

Accepted November 3, 2014

Published May 11, 2015

DOI http://dx.doi.org/10.4238/2015.May.11.29

\begin{abstract}
The traditional Chinese medicine Artemisia annua can prevent and treat hepatitis following an unclear mechanism. The aim of this study was to evaluate the effects of $A$. annua polysaccharides (AAP) on hepatitis $\mathrm{C}$ virus (HCV). A pcDNA3.1/NS3 expression vector was constructed. Ninety female BALB/c mice were randomly divided into six groups: high-dose AAP $(1 \mathrm{mg} / \mathrm{mL})+\mathrm{HCV} / \mathrm{NS} 3$ plasmid; middle-dose AAP $(0.5 \mathrm{mg} / \mathrm{mL})+\mathrm{HCV} / \mathrm{NS} 3$ plasmid; lowdose AAP $(0.1 \mathrm{mg} / \mathrm{mL})+\mathrm{HCV} / \mathrm{NS} 3$ plasmid; HCV/NS3 plasmid; high-dose AAP $(1 \mathrm{mg} / \mathrm{mL})$; normal saline control $(\mathrm{N}=15)$. Except the control group and the high-dose AAP group, other groups were inoculated with $50 \mu \mathrm{g}$ pcDNA3.1-HCV/NS3 plasmid. Serum antigenic-specific antibody was detected after the last immunization, and the levels of secreted IFN- $\gamma$ and IL-4 were measured. pcDNA3.1/ NS3 plasmid was successfully constructed, and the extracted product contained HCV/NS3 sequence. Compared with single inoculation with HCV/NS3 DNA vaccine, the specific antibody levels induced
\end{abstract}


by middle-dose AAP plus HCV/NS3 DNA vaccine were significantly different in weeks 1,3 and $5(\mathrm{P}<0.05)$. However, there were no significant differences in the antibody levels induced by high-dose and low-dose AAP as adjuvant compared with those of single inoculation with DNA vaccine $(\mathrm{P}>0.05)$. The level of serum IFN- $\gamma$ secretion was significantly higher than that of IL-4 secretion. Compared with the single HCV/NS3 DNA vaccine group, AAP plus HCV/NS3 DNA vaccine groups had significant increased IFN- $\gamma$ levels $(\mathrm{P}<0.05)$, but the IL-4 levels were not significantly different among these groups ( $\mathrm{P}$ $>0.05)$. AAP, as the adjuvant of HCV/NS3 DNA vaccine, can widely regulate the humoral immunity and cellular immune function of normal and cyclophosphamide-induced immunocompromised mice. AAP can promote IFN- $\gamma$ secretion probably by inducing Th1-type cellular immune response.

Key words: Hepatitis C virus; Artemisia annua polysaccharide; Nonstructural protein

\section{INTRODUCTION}

The hepatitis $\mathrm{C}$ virus (HCV), which is mainly transmitted through blood, is the pathogenic factor of hepatitis $\mathrm{C}$. Chronic HCV infection can lead to chronic liver inflammation, necrosis, and fibrosis, and may develop into cirrhosis or even hepatocellular carcinoma in some patients, thus greatly endangering the health and lives of patients ( $\mathrm{Li}$ et al., 2012; Marks and Jacobson, 2012). Currently, there are about 170 million HCV-infected patients worldwide, Approximately 35,000 new cases of HCV infection occur annually in China, which has become a serious social and public health issue. The common therapeutic drugs for $\mathrm{HCV}$ infection are $\alpha$-interferon and ribavirin, which have low curative rates. Therefore, DNA vaccine research is of critical clinical significance for the prevention and treatment of $\mathrm{HCV}$ infection. However, due to the high degree of variability of HCV envelope proteins, it is difficult for the neutralizing antibodies generated by vaccination to prevent and clear HCV infection effectively, resulting in prominence of the role of cellular immunity (SaalauBethell et al., 2012). In addition, after the human body is infected by HCV, the cellular immune response is weak in most people in whom chronic hepatitis can develop, while a small number of people with strong cellular immune response experience complete removal of the virus and full recovery (Rudd et al., 2012).

Artemisia annua, the drying aerial part of the Compositae A. annua L., is a commonly used traditional Chinese medicine with the functions of more moderately, minimizing response to heat, preventing malaria, and enhancing immunity (Elfawal et al., 2012). Research on $A$. аппиа mainly focuses on artemisinin and other terpenoids and their volatile oils, but studies on the polysaccharides contained in $A$. апnиa have rarely been reported. In recent years, studies have demonstrated that active polysaccharides in traditional Chinese medicines play a universal role in immunoregulation and immunoenhancement (Singh et al., 2011). Studies have also shown that $A$. аnnua polysaccharides (AAP) can effectively improve the human body's cellular immune function. Therefore, this research focused on the effects of AAP on the immune response to hepatitis $\mathrm{C}$ and its properties. 


\section{MATERIAL AND METHODS}

\section{Animals}

Female BALB/c mice (H2-d) at 5-6 weeks old were purchased from the Department of Laboratory Animal Science, Capital Medical University [certificate of conformity No. SCXK (Beijing) 2012-0046]. All the mice were gavage feeding for 2 weeks.

\section{Other reagents and apparatus}

Reagents were sourced as follows: pcDNA3.1/NS3 expression vector and HB101 bacteria (Institute of Biomedical Engineering, Chinese Academy of Medical Sciences); tryptone and yeast extract (Shanghai Baoman Bio-Tech Co., Ltd., Shanghai, China); restriction endonucleases XhoI and HindIII (Beijing Ruize Kang Technology Co., Ltd., Beijing, China); low-temperature high-speed centrifuge (Beijing Jingli Centrifuge Co., Ltd., Beijing, China); biochemical incubator (Shanghai LEAD-Tech Scientific Instrument Co., Ltd., Shanghai, China); electrophoresis apparatus (Labnet Intl., Edison, NJ, USA); UV spectrophotometer (Shanghai AoXi Technology Instrument Co., Ltd, Shanghai, China); gel imaging analysis system (Heraeus, Hanau, Germany); AAP (Changzhou Shenma Pharmaceutical Co., Ltd., Changzhou, China ); mouse interferon (IFN)- $\gamma$ and interleukin (IL)-4 enzyme-linked immunosorbent assay (ELISA) reagent kits (Santa Cruz Biotechnology, Santa Cruz, CA, USA).

\section{Construction of pcDNA3.1/NS3 expression vector}

The HCV/NS3 sequence was amplified by polymerase chain reaction (PCR) with NS3 sequence $(1467 \mathrm{~kb})$ as the template to introduce an XhoI restriction endonuclease site and initiation codon in the upstream region and an HindIII restriction site and termination codon in the downstream region. The product was purified and subjected to be joined with the PCR product of the HCV/NS3 fragment under the action of T4 ligase after digestion by the enzymes of XbarI and HindIII with pcDNA3.1 (-) as the cloning vector.

\section{Quantitative and qualitative detection of NS3 plasmid}

A UV spectrophotometer was used to detect DNA concentration and purity $\left(\mathrm{A}_{260}{ }^{\prime}\right.$ $A_{280}$ ). The extracted plasmid was digested with restriction endonucleases and confirmed by agarose gel electrophoresis. Reaction system $(20 \mu \mathrm{L})$ : DNA $0.2-1 \mu \mathrm{g}, 10 \mathrm{X}$ buffer $2.0 \mu \mathrm{L}$, restriction enzyme $1-2 \mu \mathrm{L}$, add $\mathrm{ddH}_{2} \mathrm{O}$ to $20 \mu \mathrm{L}$.

\section{Animal grouping and immune inoculation}

A total of $90 \mathrm{BALB} / \mathrm{c}$ mice were randomly divided into six groups $(\mathrm{N}=15): 1)$ highdose AAP $(1 \mathrm{mg} / \mathrm{mL})+\mathrm{HCV} / \mathrm{NS} 3$ plasmid; 2$)$ middle-dose AAP $(0.5 \mathrm{mg} / \mathrm{mL})+\mathrm{HCV} / \mathrm{NS} 3$ plasmid; 3) low-dose AAP (0.1 mg/mL) + HCV/NS3 plasmid; 4) HCV/NS3 plasmid; 5) highdose AAP (1 mg/mL); and 6) normal saline control. Except for the control group and the high-dose AAP group, the mice of each group were inoculated with $50 \mu \mathrm{g}$ (time/mouse) of 
pcDNA3.1-HCV/NS3 plasmid by multi-point injection in the quadriceps femoris, a total of 5 weeks, and the immune reaction was boosted once 7 days later. Meanwhile, the mice of groups $1,2,3$, and 5 were intragastrically provided with corresponding doses of AAP after each immunization, and gavage was conducted once every other day, during which the body weights of mice and unusual circumstances were closely monitored.

\section{Detection of serum antigenic-specific antibody}

Tail blood was collected in weeks 1,3 , and 5 after the last immunization, and separated to collect serum, which was stored at $-20^{\circ} \mathrm{C}$. The mouse serum-specific immunoglobulin (IgG) antibody levels were detected by indirect ELISA, and the absorbance at $450 \mathrm{~nm}$ was detected on a microplate reader.

\section{Cytokine detection}

Eyeball blood was collected 10 days after booster immunization for serum preparation to determine the IFN- $\gamma$ and IL-4 secretion levels.

\section{Statistical analysis}

SPSS 15.0 (SPSS, Chicago, IL, USA) was used for data analysis. The measurement data are reported as means \pm standard deviation (SD). The measurement data and the numeration data of groups were compared by a group-design Student $t$-test and a $\chi^{2}$ test, respectively. The significance level was bilateral $\alpha=0.05$.

\section{RESULTS}

\section{Determination of pcDNA3.1/NS3 concentration and purity}

The purified and extracted plasmid was measured with a UV spectrophotometer. The range of plasmid concentration was $9.5-10.5 \mu \mathrm{g} / \mathrm{mL}$, and the purity reached 0.90 or above (Table 1). The required DNA concentration for mouse immunization was $10 \mu \mathrm{g} / \mathrm{mL}$, indicating that the extracted DNA met the requirements for concentration and purity.

$$
\text { Table 1. pcDNA3.1/NS3 concentration and purity }\left(\mathrm{A}_{260} / \mathrm{A}_{280}\right) \text {. }
$$

\begin{tabular}{lccccc}
\hline & \multicolumn{5}{c}{ Sample } \\
\cline { 2 - 6 } & 1 & 2 & 3 & 4 & 5 \\
\hline DNA concentration $(\mu \mathrm{g} / \mathrm{mL})$ & 9.75 & 10.16 & 9.82 & 10.08 & 9.68 \\
DNA purity $\left(\mathrm{OD}_{260} / \mathrm{OD}_{280}\right)$ & 1.62 & 1.69 & 1.71 & 1.67 & 1.68 \\
\hline
\end{tabular}

\section{Agarose gel electrophoresis results}

The theoretical length of the NS3 gene in HCV should be $1673 \mathrm{bp}$. The electrophoretic bands of the extracted product after digestion are shown in Figure 1. There was a clear band at 
$1700 \mathrm{bp}$ in the same position as that of the band obtained after electrophoresis of the digested pcDNA3.1/NS3 plasmid. The results confirmed that the extracted product contained the HCV/ NS3 sequence.

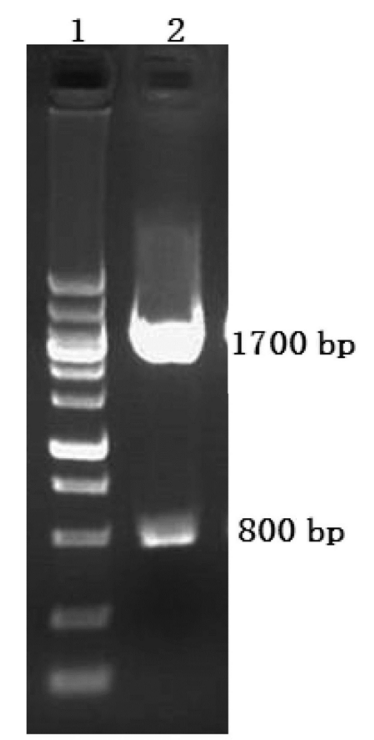

Figure 1. Agarose gel electrophoresis analysis of the HCV-NS3 plasmid. Lane 1: marker; Lane 2: pCDNA3.1/NS3 plasmid.

\section{Serum antigenic-specific IgG level}

Figure 2 shows that different levels of antibodies were generated in immunized mice of each group in the first week after the second immunization. Compared with single vaccination with the HCV/NS3 DNA vaccine, the specific antibody levels induced by middle-dose AAP plus HCV/NS3 DNA vaccine were significantly different in weeks 1,3 , and $5(\mathrm{P}<0.05)$. However, there were no significant differences in the antibody levels induced by the high-dose and low-dose AAP as adjuvant compared with single vaccination with DNA vaccine alone $(\mathrm{P}>0.05)$. With elapsed time, the specific IgG levels rose in both the middle-dose AAP plus $\mathrm{HCV} / \mathrm{NS} 3 \mathrm{DNA}$ vaccine group and the single DNA vaccine group; this trend, however, did not appear in the high- and low-dose AAP immunoadjuvant groups (Figure 2).

\section{Cytokine detection}

Overall, the level of serum IFN- $\gamma$ secretion was significantly higher than that of IL-4 secretion. Compared with the single HCV/NS3 DNA vaccine group, the AAP plus HCV/NS3 DNA vaccine groups had significantly increased IFN- $\gamma$ secretion $(\mathrm{P}<0.05)$. In particular, the IFN- $\gamma$ secretion level was the highest in the middle-dose AAP plus DNA vaccine group, with the difference being statistically significant $(\mathrm{P}<0.01)$. However, the secretion levels of IFN- $\gamma$ were not increased with elevating dosage of AAP. The IL-4 secretion levels were not significantly different among the groups $(\mathrm{P}>0.05)$. The IFN- $\gamma$ secretion level was also increased in the AAP group of single high-dose administration (Figure 3). 


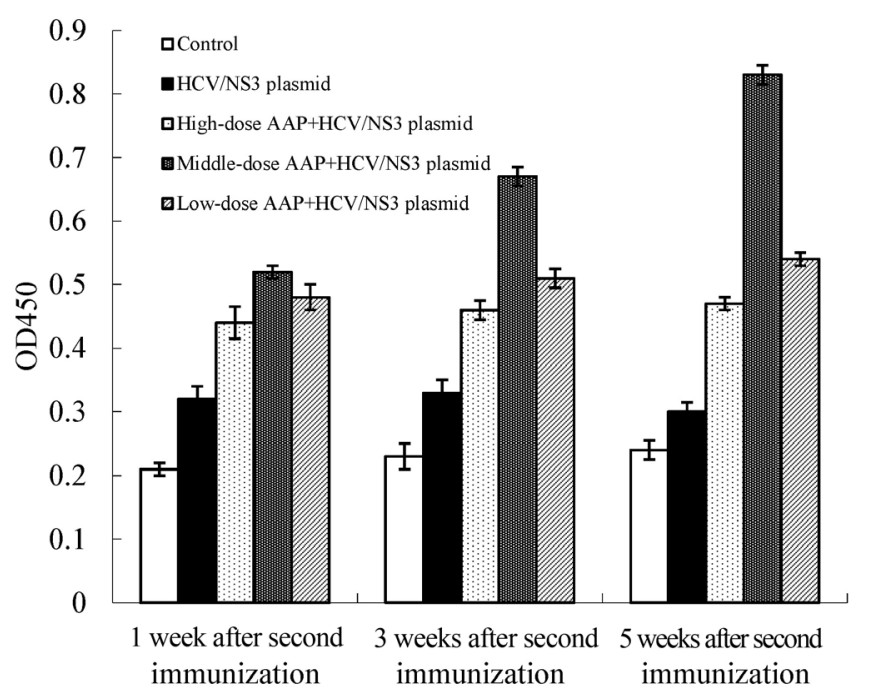

Figure 2. Effects of AAP on serum antigenic-specific IgG levels. Comparison is with the single DNA vaccination group, $\mathrm{P}<0.05$. AAP $=$ Artemisia annua polysaccharides.

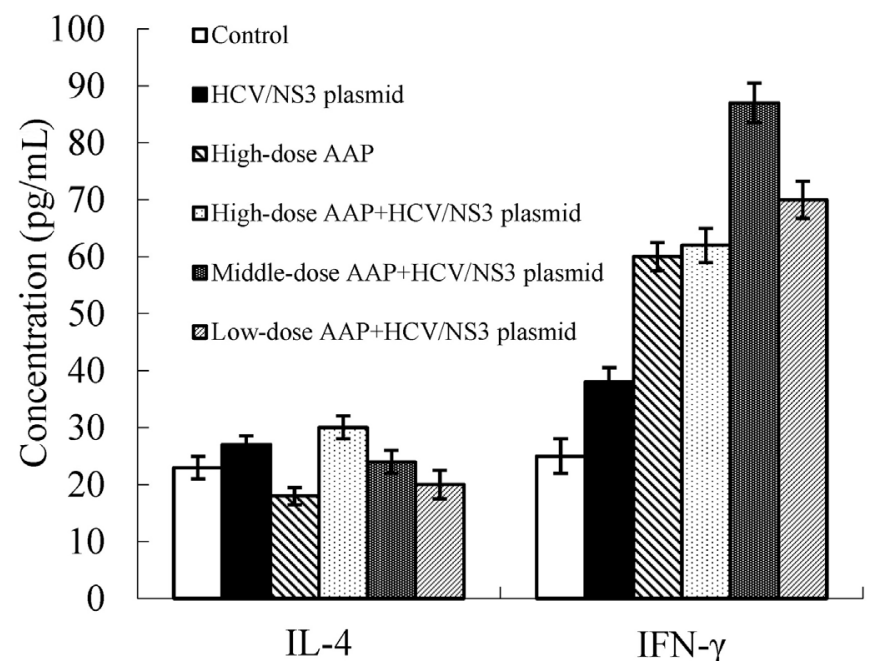

Figure 3. Effects of AAP plus HCV NS3 on serum cytokine levels. AAP = Artemisia annua polysaccharides.

\section{DISCUSSION}

$\mathrm{HCV}$, a single-stranded positive-sense RNA virus with a full-length genome of $916 \mathrm{~kb}$, consists of a 5'-untranslated region, a 3'-untranslated region, and a single central open reading frame (ORF). The ORF can encode a poly-protein precursor composed of approximately 3000 amino acids. The ORF in the viral genome can be first translated into a multi-protein form, and then processed into more than 10 kinds of structural and nonstructural proteins under the action of the HCV viral protease and signal peptide enzymes of the host cells (Besse et al., 2012; Shiryaev et al., 2012). The T and B lymphocyte epitope prediction of HCV genome se- 
quences and clinical and basic research suggest that there might be multiple $\mathrm{T}$ and $\mathrm{B}$ lymphocyte epitopes in the NS3 region. The HCV nonstructural protein NS3-encoded virus helicase and protease have highly conserved amino acid sequences (Gupte and Arankalle, 2012). According to clinical reports, the NS3 region plays an important role in the HCV replication cycle. Antibodies targeting the anti-NS3 area appear in the early stages of infection, usually earlier than or simultaneously with the core antibody. Immunization in vivo experiments have shown that CD4+ and $\mathrm{CD} 8+$ response induced by $\mathrm{HCV}$ core antigen $\mathrm{C}$ dendritic cells are weaker than that induced by HCV/NS3 gene-modified dendritic cells (Peres-da-Silva et al., 2012; Vicenti et al., 2012).

Plasmids are commonly used DNA cloning vectors. The plasmid used in this study was pcDNA3.1, containing an anti-AMP gene and a CMV promoter. XhoI and HindIII restriction sites were introduced by primer design; these enzymes were then selected for the digestion and enzymolysis of the NS3 plasmid DNA. Higher animals can produce specific immune responses to virus infection, including humoral immunity and cellular immunity. The former is manifested through $\mathrm{B}$ cells, which produce neutralizing antibodies that can eliminate the infection ability of viruses through binding, thus playing a major role in eliminating extracellular free virus (Thomas et al., 2012; Zhu et al., 2012). The mechanisms of action of the antibodies are to change the virus surface configuration, or to combine with virus epitopes adsorbed on susceptible cell receptors to prevent virus adsorption and invasion into susceptible cells for proliferation (Estrabaud et al., 2011). In addition, after cells are infected by enveloped virus, virus-encoded protein may appear on the membrane to bind with a corresponding antibody for cell lysis with the participation of a complement or to break open and destroy virus-infected cells through antibody-dependent cell-mediated cytotoxicity (Ke and Chen, 2011). Due to the high variability of $\mathrm{HCV}$ envelope glycoprotein, it is difficult for the generated neutralizing antibodies to prevent and eliminate virus infection in an effective way; however, it is also necessary to consider the important role that humoral immunity plays in HCV infection.

Traditional Chinese medicines are efficient biological response modifiers, which generally have the effect of enhancing immune function with no toxic or side effects on normal cells, and thus are promising for development into new vaccine adjuvants. The combination of traditional Chinese medicines with vaccines plays a certain role in both prevention and treatment of diseases, potentially taking an adjuvant effect (Yeh et al., 2011; He et al., 2012). Therefore, to search for suitable adjuvants from traditional Chinese medicines with immune activities is a meaningful subject for research in artificial immunity. Studies have shown that AAP has a wide range of regulatory functions in the humoral and cellular immunity of normal and immunocompromised mice induced by cyclophosphamide (Misra et al., 2012). Moreover, AAP shows capacity for promoting B lymphocytes to synthesize IgG and IgM in animal studies, and can also improve the IgA levels in immunocompromised patients, increasing the numbers of spleen antibody-secreting cells and specific rosette formation (Zhai et al., 2010). Therefore, this study used AAP as the immune adjuvant for an HCV/NS3 DNA vaccine to observe the effect of their joint application on humoral immune response.

The analysis of the detection of cytokine secretion levels suggested that AAP plays a role in promoting IFN- $\gamma$ secretion, and many previous studies also have confirmed that AAP has a function in stimulating IFN formation (Rezvan, 2013). Consistent with the results of antibody-level studies, AAP, as an adjuvant, is also not dose-dependent for the secretion of IFN- $\gamma$. Middle-dose AAP was the most ideal adjuvant for joint induction of IFN- $\gamma$ level with DNA vaccination, which seemed to further confirm that high-dose AAP may have an immunosuppressive effect. The IL-4 level detected in each group was significantly lower than the 
IFN- $\gamma$ level. IFN- $\gamma$ is a Th1-characteristic cytokine, and IL-4 is a Th2-characteristic cytokine. This result suggested that AAP might be more effective as an adjuvant in the induction of Th1 cellular immune response. However, the increase in IFN- $\gamma$ secretion could also directly promote the differentiation of B cells, and meanwhile stimulate B cells to secrete antibodies, also potentially enhancing the humoral immune response to some extent (Olofsson et al., 2012).

In summary, middle-dose AAP showed an adjuvant effect on HCV/NS3 DNA vaccine-induced antibody levels and cytokine secretion. However, the mechanism by which AAP enhanced humoral immune response still needs to be further explored.

\section{ACKNOWLEDGMENTS}

Research supported by the Nature Science Foundation of the Inner Mongolia Autonomous Region (\#2013MS1224), a Scientific Project of the Affiliated Hospital of Inner Mongolia Medical University (\#NYFY2010YB006), the Youth Innovation Fund of Inner Mongolia Medical University (\#NY2010QN002), and the Key Scientific Fund of the Affiliated Hospital of Inner Mongolia Medical University (\#NYFYZD20130158).

\section{REFERENCES}

Besse B, Coste-Burel M, Bourgeois, M, Feray C, et al. (2012). Genotyping and resistance profile of hepatitis C (HCV) genotypes 1-6 by sequencing the NS3 protease region using a single optimized sensitive method. J. Virol. Methods 185: 94-100.

Elfawal MA, Towler MJ, Reich NG, Golenblock D, et al. (2012). Dried whole plant Artemisia annua as an antimalarial therapy. PLoS One 7: e52746.

Estrabaud E, De Muynck S and Asselah T (2011). Activation of unfolded protein response and autophagy during HCV infection modulates innate immune response. J. Hepatol. 55: 1150-1153.

Gupte GM and Arankalle VA (2012). Evaluation of the immunogenicity of liposome encapsulated HVR1 and NS3 regions of genotype $3 \mathrm{HCV}$, either singly or in combination. Virol. J. 9: 74.

He FY, Deng KW, Zeng JL, Dai RW, et al. (2012). Current state of studies on screening method for sensitinogens in injections for traditional Chinese medicine and synthetic immunity method. Zhongguo Zhong Yao Za Zhi 37: 2836-2841.

Ke PY and Chen SS (2011). Autophagy: a novel guardian of HCV against innate immune response. Autophagy 7: 533-535.

Li X, Liu Y, Zhang YK, Plattner JJ, et al. (2012). Synthesis and antiviral activity of novel HCV NS3 protease inhibitors with P4 capping groups. Bioorg. Med. Chem. Lett. 22: 7351-7356.

Marks KM and Jacobson IM (2012). The first wave: HCV NS3 protease inhibitors telaprevir and boceprevir. Antivir. Ther. 17: 1119-1131.

Misra A, Chanotiya CS, Gupta MM, Dwivedi UN, et al. (2012). Characterization of cytochrome P450 monooxygenases isolated from trichome enriched fraction of Artemisia annua L. leaf. Gene 510: 193-201.

Olofsson L, Lundgren A and Brodelius PE (2012). Trichome isolation with and without fixation using laser microdissection and pressure catapulting followed by RNA amplification: expression of genes of terpene metabolism in apical and sub-apical trichome cells of Artemisia annua L. Plant Sci. 183: 9-13.

Peres-da-Silva A, Almeida AJ and Lampe E (2012). Genetic diversity of NS3 protease from Brazilian HCV isolates and possible implications for therapy with direct-acting antiviral drugs. Mem. Inst. Oswaldo Cruz 107: 254-261.

Rezvan H (2013). Immunogenicity of HLA-DR1 Restricted Peptides Derived from Leishmania major gp63 Using FVB/NDR1 Transgenic Mouse Model. Iran J. Parasitol. 8: 273-279.

Rudd MT, McCauley JA, Romano JJ, Butcher JW, et al. (2012). Development of potent macrocyclic inhibitors of genotype 3a HCV NS3/4A protease. Bioorg. Med. Chem. Lett. 22: 7201-7206.

Saalau-Bethell SM, Woodhead AJ, Chessari G, Carr MG, et al. (2012). Discovery of an allosteric mechanism for the regulation of HCV NS3 protein function. Nat. Chem. Biol. 8: 920-925.

Schiering N, D'Arcy A, Villard F, Simic O, et al. (2011). A macrocyclic HCV NS3/4A protease inhibitor interacts with protease and helicase residues in the complex with its full-length target. Proc. Natl. Acad. Sci. U. S. A. 108: 21052-21056.

Shiryaev SA, Thomsen ER, Cleplak P, Chudin E, et al. (2012). New details of HCV NS3/4A proteinase functionality revealed by a high-throughput cleavage assay. PLoS One 7: e35759. 
Singh NP, Ferreira JF, Parks JS and Lai HC (2011). Cytotoxicity of ethanolic extracts of Artemisia annua to Molt-4 human leukemia cells. Planta Med. 77: 1788-1793.

Thomas E, Gonzalez VD, Li Q, Modi AA, et al. (2012). HCV infection induces a unique hepatic innate immune response associated with robust production of type III interferons. Gastroenterology 142: 978-988.

Vicenti I, Rosi A, Saladini F, Meini G, et al. (2012). Naturally occurring hepatitis C virus (HCV) NS3/4A protease inhibitor resistance-related mutations in HCV genotype 1-infected subjects in Italy. J. Antimicrob. Chemother. 67: 984-987.

Yeh HS, Weng BC and Lien TF (2011). Effects of Chinese traditional herbal medicine complex supplementation on the growth performance, immunity and serum traits of pigs. Anim. Sci. J. 82: 747-752.

Zhai DD, Supaibulwatana K and Zhong JJ (2010). Inhibition of tumor cell proliferation and induction of apoptosis in human lung carcinoma 95-D cells by a new sesquiterpene from hairy root cultures of Artemisia annua. Phytomedicine 17: 856-861.

Zhu W, Wu C, Deng W, Pei R, et al. (2012). Inhibition of the HCV core protein on the immune response to HBV surface antigen and on HBV gene expression and replication in vivo. PLoS One 7: e45146. 